University of Nebraska - Lincoln

DigitalCommons@University of Nebraska - Lincoln

\title{
Reducing Corrosion of Additive Manufactured Magnesium Alloys by Interlayer Ultrasonic Peening
}

\author{
M. P. Sealy \\ R. Karunakaran \\ S. Ortgies \\ G. Madireddy
}

A. P. Malshe

See next page for additional authors

Follow this and additional works at: https://digitalcommons.unl.edu/mechengfacpub

Part of the Mechanics of Materials Commons, Nanoscience and Nanotechnology Commons, Other Engineering Science and Materials Commons, and the Other Mechanical Engineering Commons

This Article is brought to you for free and open access by the Mechanical \& Materials Engineering, Department of at DigitalCommons@University of Nebraska - Lincoln. It has been accepted for inclusion in Mechanical \& Materials Engineering Faculty Publications by an authorized administrator of DigitalCommons@University of Nebraska Lincoln. 
Authors

M. P. Sealy, R. Karunakaran, S. Ortgies, G. Madireddy, A. P. Malshe, and K. P. Rajurkar 
Published in CIRP Annals - Manufacturing Technology 70 (2021), pp. 179-182; doi: 10.1016/j.cirp.2021.04.052 Copyright (C) 2021 CIRP. Published by Elsevier Ltd. Used by permission.

Published online June 8, 2021.

\title{
Reducing Corrosion of
}

\section{Additive Manufactured Magnesium Alloys by Interlayer Ultrasonic Peening}

\author{
M. P. Sealy, ${ }^{1}$ R. Karunakaran, ${ }^{1}$ S. Ortgies,${ }^{1}$ G. Madireddy,${ }^{1}$
}

\author{
A. P. Malshe, ${ }^{2}$ and K. P. Rajurkar ${ }^{1}$
}

1. Department of Mechanical and Materials Engineering, University of Nebraska-Lincoln, Lincoln, Nebraska, USA

2. School of Mechanical Engineering, Purdue University, West Lafayette, Indiana, USA

Corresponding author - M. P. Sealy, email sealy@unl.edu

\begin{abstract}
Additive manufad (AM) magn alloys corrode rapidly due to tensile stress and coarse microstructures. Cyclically combining (hybridizing) additive manufacturing with interlayer ultrasonic peening was proposed as a solution to improve corrosion resistance of additive manufactured magnesium WE43 alloy through strengthening mechanisms and compressive residual stress. Applying interlayer peening work hardened discrete layers and formed a glocal integrity of regional grain refinement and subsurface compressive residual stress barriers. Tensile residual stress that typically accelerates corrosion decreased $90 \%$. Results showed time-resolved control over corrosion was attainable by interlayer peening, and local corrosion within print cells decreased $57 \%$ with respect to as-printed WE43.
\end{abstract}

Keywords: additive manufacturing, hybrid manufacturing, magnesium

\section{Introduction}

As magnesium additive manufacturing progresses to higher technology readiness levels [1], medical device and oil fracking industries seek time-resolved degradation of load- 
bearing devices that capitalize on the advantages of 3D printing. Magnesium components for these industries need to maintain structural integrity for a designated time in a highly corrosive service environment. Complete dissolution is desired once the intended servicelife has concluded. For example, bioresorbable orthopedic implants with time dependent strength and integrity are desired for delivering anti-inflammatory drugs over several weeks to manage post-operative pain and expedite bone recovery. Also, magnesium alloys are deployable in oil wells as degradable plugs with time-resolved strength during hydraulic fracking. These plugs provide high-pressure isolation in bore wells and dissolve completely in days without debris or pipe clogging. Time-resolved control on degradation is attainable by spatially dictating corrosion resistance throughout a volume using hybridAM. The use of interlayer cold working during additive manufacturing enables functionalized interfacial properties within magnesium. This research aims to understand the cumulative formation of these 3D mechanical properties (i.e., glocal integrity) and the resulting corrosion behavior from interlayer ultrasonic peening.

The term "glocal integrity" refers to local changes within layers that accumulate during cyclic printing and interlayer cold working [2] that ultimately affects global behavior [3]. Understanding the mechanisms driving global behavior remains a critical knowledge gap in hybrid additive manufacturing research. The approach employs ultrasonic peening on a degradable magnesium WE43 alloy every twenty layers during powder bed fusion. Although surface peening is known to induce work hardening, grain refinement, and compressive residual stress initially delays corrosion [4], the problem is rapid and uncontrolled corrosion occurs once the surface treated layer dissolves. The underlying hypothesis for subsurface barrier regions that inhibit corrosion postulates that annealing caused by subsequent printing on peened layers retains a favorable glocal integrity. Explicitly, how can strength be maintained in a part designed to dissolve? Thus, the objectives of this research are to identify the dominant corrosion phenomenon in printed WE43 and study how strengthening mechanisms and residual stress caused by interspersing peened barrier layers inhibit corrosion.

The following subsections discuss corrosion of additive manufactured magnesium alloys and the need for hybrid-AM. Section 2 describes hybrid-AM of WE43, including identifying a formation zone for printing and interlayer ultrasonic peening during powder bed fusion. Material properties, including soot formation, are characterized in Section 3, and the resulting effect on corrosion behavior is discussed in Section 4. The last section summarizes this study.

\subsection{Time-resolved degradation of load-bearing magnesium alloys}

Current manufacturing technologies to reduce magnesium corrosion include (1) bulk properties changes through alloying or forming [5] (i.e., uniform corrosion) or (2) surface treatments/coatings [4] (i.e., non-uniform corrosion). These processes are unable to achieve spatial and temporal control of corrosion throughout a component's volume. Any change in chemical composition in highly regulated applications, such as biomedical implants, warrants extensive testing that requires additional time and resources [6]. Further, coatings possess lackluster performance due to poor scratch resistance, and surface treatments are ineffective for maintaining strength once corrosion propagates into underlying bulk 
regions. Thus, advanced production technologies are needed to achieve corrosion control of degradable magnesium alloys throughout an entire build volume. Without such processes, the ability to maintain strength under guided corrosion remains a major limitation.

\subsection{Corrosion of additive manufactured magnesium alloys}

A key technical challenge in printing WE43 is identifying a process window that reduces the propensity for "balling effect" and incomplete melting of powder (energy density too low) or vaporization (energy density too high) [7]. The formation zone depends on the chemical composition and morphology of WE43 powder, print environment, and AM process parameters. Vaporization of elements or increased surface area from lack of fusion accelerate magnesium corrosion. Powder bed fusion (PBF) is the most widely investigated AM production process for magnesium alloys and is still not well understood due to complications involved in printing. Particles range in size from $25 \mu \mathrm{m}$ to $150 \mu \mathrm{m}$ and have a high surface energy that is prone to oxidation. Thus, care must be taken to print under an inert atmosphere to avoid a volatile reaction. The ideal inert atmosphere is still under investigation. The addition of $2 \%$ hydrogen gas in argon was proposed to improve density [8], but the lack of statistically significant results and the risk of an oxyhydrogen detonation reaction limits feasibility. Magnesium's low melting point $\left(650^{\circ} \mathrm{C}\right)$ in comparison to boiling point $\left(1093^{\circ} \mathrm{C}\right)$ further complicates printing due to excessive vaporization rather than melting. PBF of magnesium exhibits a wide range of energy densities from 14 to $1250 \mathrm{~J} / \mathrm{mm}^{3}$ (Fig. 1) $[9,10]$. WE43 used in this research has a lower melting and vaporization temperature compared to other magnesium alloys. As such, experiments were restricted to 25-100 $\mathrm{J} / \mathrm{mm}^{3}$.
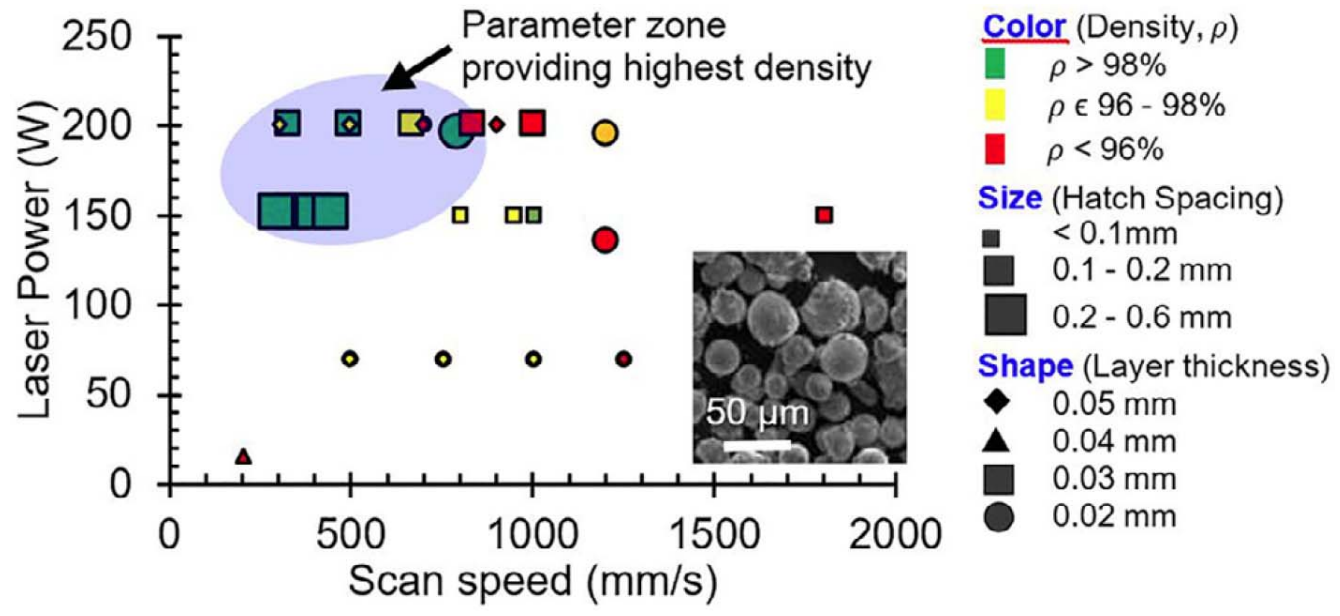

Figure 1. PBF process parameter map for Mg alloys. Modified from [9].

Magnesium alloys placed in aqueous environments form a corrosion-resistant protective coating of magnesium hydroxide, $\mathrm{Mg}(\mathrm{OH})_{2}$. The protective hydroxide coating becomes unstable and porous in chloride environments due to the formation of soluble magnesium chloride [11]. As a result, the protective hydroxide film on magnesium 
becomes porous and leads to severe pitting corrosion. The corrosion rate is primarily driven by surface chemistry, stress, and topography. Printed WE43 was found to corrode excessively (5-7.2 mm/yr) due to tensile residual stress compared to $0.8-1.2 \mathrm{~mm} / \mathrm{yr}$ for cast WE43 [12]. A solution is to use hybrid-AM to reduce excessive corrosion. Hybrid-AM couples printing with interlayer secondary processes, such as ultrasonic peening, to modify the surface integrity of temporarily accessible layers [13]. Interlayer ultrasonic peening causes localized severe plastic deformation leading to grain refinement and compressive residual stress [14]. This research investigates interlayer ultrasonic peening to mitigate corrosion of WE43 from PBF.

\section{Hybrid additive manufacturing of WE43}

\subsection{Identifying a formation zone for WE43}

Components were printed on a Matsuura Lumex Avance-25 equipped with an Yb-fiber laser with a $0.2 \mathrm{~mm}$ spot size. Spherical WE43 powder (Luxfer MEL Tech.) with an average diameter of $28 \pm 7 \mu \mathrm{m}$ was deposited on $38 \mathrm{~mm}$ thick precision ground ZK60A magnesium baseplate in an argon atmosphere (less than $1.5 \% \mathrm{O}_{2}$ ). The $\mathrm{D}_{10}$, $\mathrm{D}_{50}$, and $\mathrm{D}_{90}$ were 20,26 , and $39 \mu \mathrm{m}$, respectively. The theoretical layer thickness was $50 \mu \mathrm{m}$. The actual layer thickness after ultrasonic peening was larger due to plastic deformation.

A series of pilot studies were initiated to determine a formation zone where (1) the melt pool depth penetrated two printed layers (i.e., $100 \mu \mathrm{m}$ ) for adequate bonding and (2) the melt pool width $(150 \mu \mathrm{m})$ achieved $20 \%$ to $50 \%$ overlap between adjacent rasters (Fig. 2a). No key-holing or lack of fusion was observed in these melt pools. Cuboids of $10 \times 10 \times 4$ $\mathrm{mm}^{3}$ were printed to determine parameter sets that yielded the highest density based on laser powers (135 W and $200 \mathrm{~W})$ and scan speeds $(500 \mathrm{~mm} / \mathrm{s}$ and $700 \mathrm{~mm} / \mathrm{s})$ from single track experiments having an optimal melt pool (Figs. $2 \mathrm{~b}$ and $2 \mathrm{c}$ ). The hatch spacings were $0.08 \mathrm{~mm}, 0.10 \mathrm{~mm}$, and $0.12 \mathrm{~mm}$. All printed WE43 cuboids had a minimum density of $96 \%$ as per the Archimedes method. The parameter set with laser power, scanning speed, and hatch spacing of $135 \mathrm{~W}, 700 \mathrm{~mm} / \mathrm{s}$, and $0.12 \mathrm{~mm}$ yielded the highest density of $99.89 \%$ (Archimedes) and 98\% (X-ray CT) (Fig. 2d). The corresponding energy density was 32.1 $\mathrm{J} / \mathrm{mm}^{3}$. 

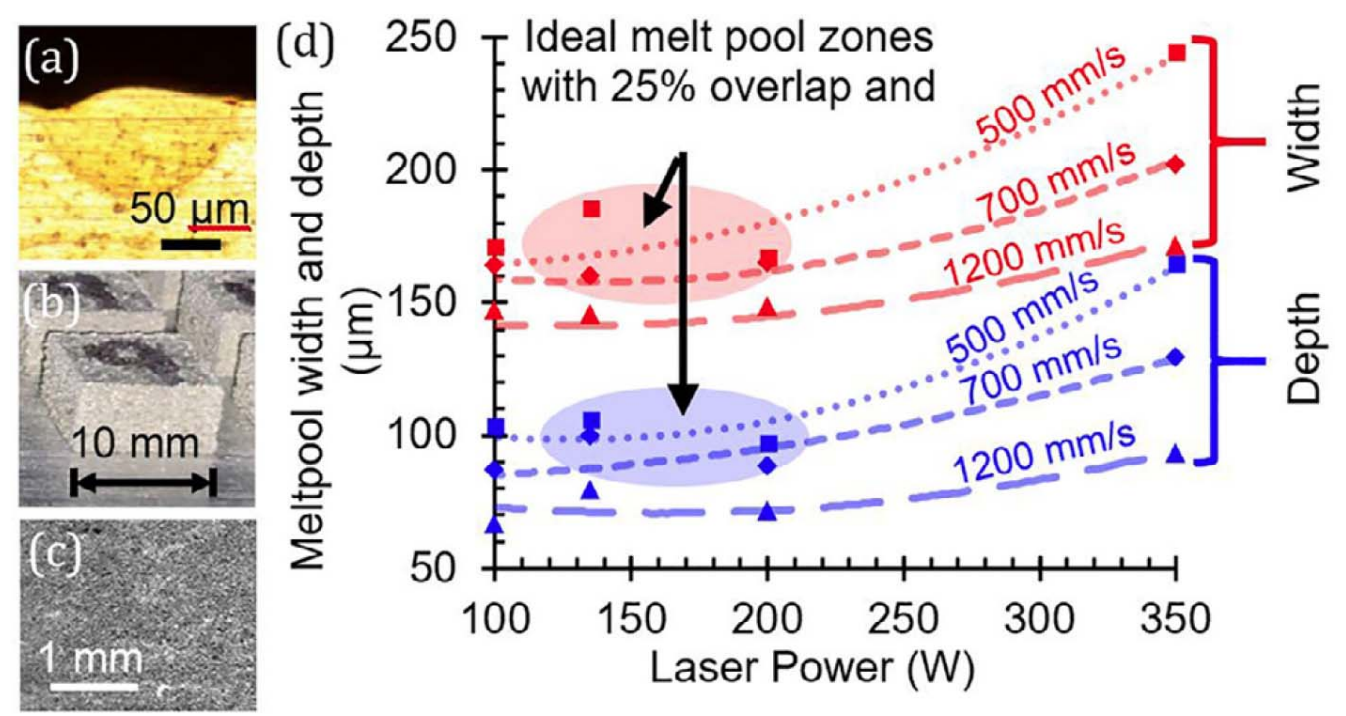

Figure 2. PBF of WE43: (a) single-track melt pool, (b) cuboid, (c) CT scan of high density cross section printed with $32.1 \mathrm{~J} / \mathrm{mm}^{3}$, and (d) single-track process map optimizing melt pool dimensions.

\subsection{Interlayer ultrasonic peening during powder bed fusion (PBF)}

All subsequent samples for this research were printed with the optimized parameter set described above. Interlayer peening was accomplished using an ultrasonic probe with $110 \mathrm{~W}$ output power and $20 \mathrm{kHz}$ frequency mounted to a linear stage. The probe had four ultrasonically vibrating needles that redistributed stress and caused surface hardening, as shown in Figure 3. The needles were $3 \mathrm{~mm}$ in diameter and evenly spaced from each other by $2 \mathrm{~mm}$. All hybrid-AM samples were 100 layers tall (i.e., $5 \mathrm{~mm}$ ) and ultrasonically peened on the 80th (i.e., $4 \mathrm{~mm}$ from the bottom) and 100th layers. Using hybrid terminology, the layer treatment frequency was L20 for two cycles starting from layer 100 (i.e., top surface). Twenty layers was chosen because prior experiments revealed that higher layer treatment frequencies induced cracking and lower frequencies failed to produce sufficient compressive residual stress to measure by hole-drilling. A $2 \mathrm{~mm}$ machining allowance was added for baseplate separation. Experimental controls consisted of as-printed samples that continuously printed without intermittent pausing and thermally matched samples that were printed with pauses to match thermal cycles from hybrid-AM. Matching thermal cycles allowed for differentiation between the effects of dwell times and interlayer ultrasonic peening during printing. Results were compared to an as-rolled WE43 control. 


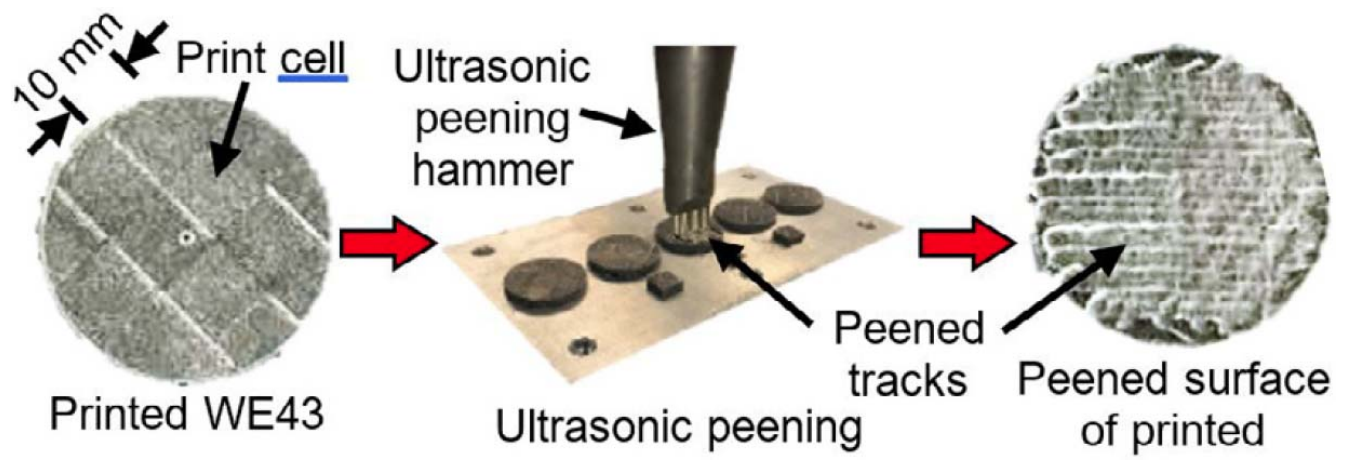

Figure 3. Inter-layer ultrasonic peening during PBF.

\section{Material characterization of hybrid PBF printed WE43}

\subsection{Microstructure analysis}

The microstructure was evaluated for as-printed, thermally matched, and hybrid-AM WE43 samples by cross-sectioning through the center parallel to the build direction and polished using $0.3 \mu \mathrm{m}$ agglomerate free alpha alumina with isopropyl alcohol as lubricant. Etching with ethanol and 2\% nitric acid revealed unmelted powder and yttrium oxide flakes distributed throughout printed samples (Fig. 4a) similar to [15]. Grain morphology changed from rose-shaped to cellular fine grains at melt pool boundaries similar to [16]. The rose-like grains had a width of $3.5 \pm 1.3 \mu \mathrm{m}$, while cellular grains were finer with $0.4 \pm$ $0.1 \mu \mathrm{m}$ width. The rose-shaped grains increased in size away from the melt pool boundaries whereas cellular grains exhibited consistent width. Hybrid-AM by peening showed equiaxed grain refinement due to severe plastic deformation (Fig. 4b). A $20 \mu \mathrm{m}$ grain refined zone was observed $1 \mathrm{~mm}$ from the top surface that was consistent with an L20 layer peening frequency.
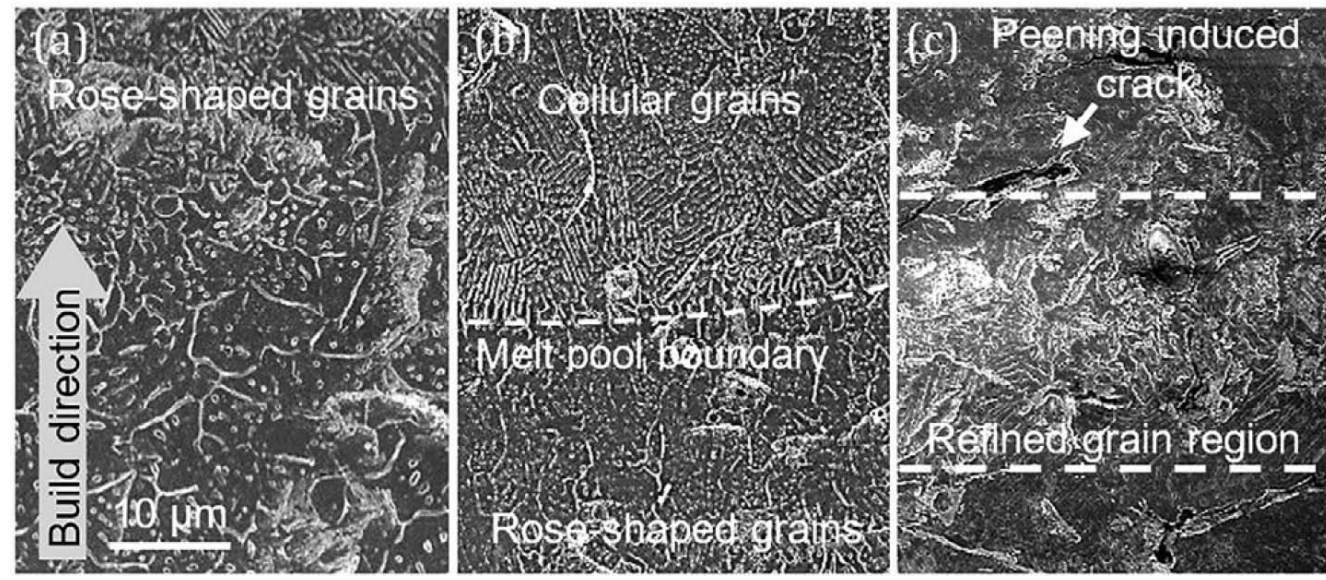

Figure 4. Representative microstructure of (a) as-printed and (b) thermally matched, and (c) refined grains in Hybrid-AM WE43 at 1.2mm depth. 


\subsection{Microhardness}

Regional Vicker's microhardness (load: $10 \mathrm{~g}_{\mathrm{f}}$ and dwell: $10 \mathrm{~s}$ ) of printed and hybrid WE43 is shown in Figure 5. As-printed samples with no pauses during printing exhibited higher hardness on average $(98.6 \pm 7.2 \mathrm{HV})$ compared to thermally matched samples $(89.9 \pm 11.2$ $\mathrm{HV}$ ) that were cycled in and out of the print chamber on the 80th and 100th layers. Higher porosity near the 80th layer was a likely reason for the lower hardness of thermally matched WE43. Ultrasonic peening increased microhardness in the first $(15 \%)$ and third interval $(10 \%)$ compared to the thermally match condition since these intervals represent peened regions. Work hardening from ultrasonic peening did not extend into the second and fourth intervals in a statistically significant manner.
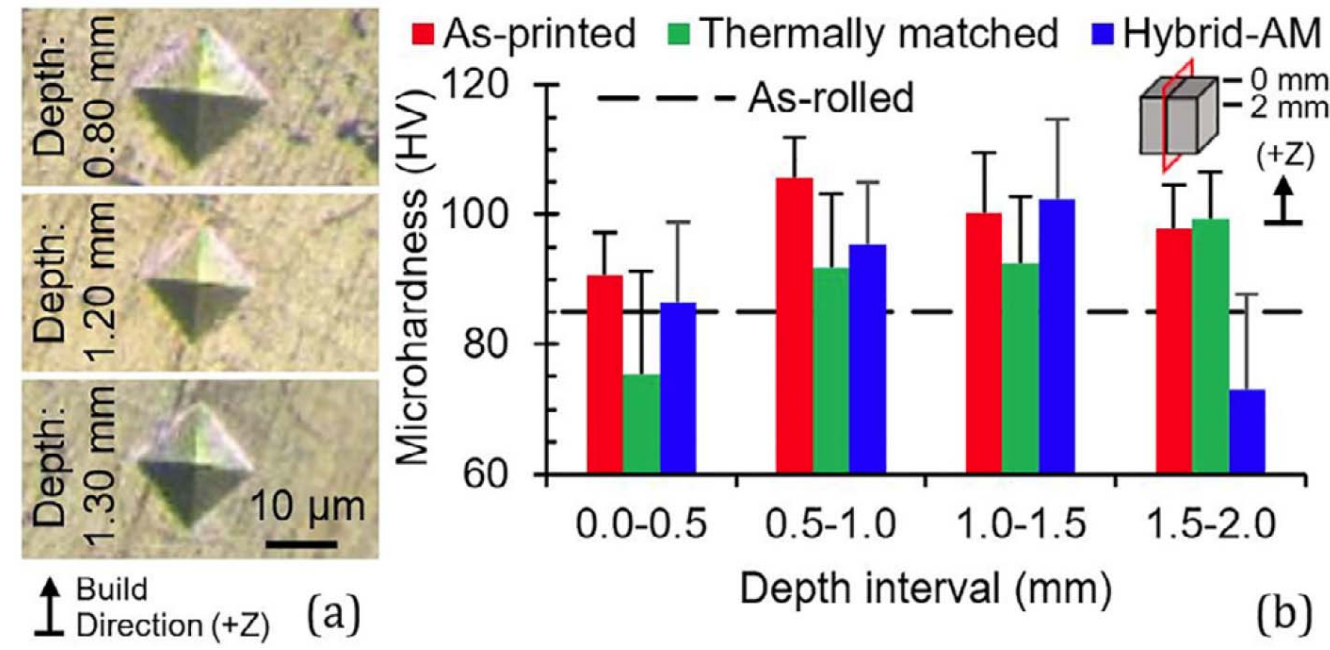

Figure 5. (a) Representative Vicker's indents and (b) regional microhardness at various depths in printed WE43.

\subsection{Residual stress by hole drilling}

Printed metals accumulate tensile stress in upper layers that aggravates corrosion. Plastic deformation by interlayer ultrasonic peening redistributed stress in printed WE43. Redistributed stress was measured on the top surface of $12 \mathrm{~mm} \times 12 \mathrm{~mm} \times 5 \mathrm{~mm}$ cuboids by holedrilling according to ASTM E837 (Fig. 6a). All hole-drilling experiments were performed while printed parts remained attached to the baseplate. Both as-printed and thermally matched WE43 exhibited predominate tensile residual stress (Fig. 6b). Interlayer peening induced compressive residual stress to a depth of $0.4 \mathrm{~mm}$ after which tensile stress was observed. The stress in hybrid-AM WE43 again turned compressive at a depth of $1 \mathrm{~mm}$ that corresponded with the location of ultrasonic peening. The flipping of residual stress from tensile to compressive at $1 \mathrm{~mm}$ depth displays the hypothesized effectiveness of hybridAM technology to locally control behavior of printed parts. Hybrid-AM reduced stress in the top $1 \mathrm{~mm}$ of printed parts on average by $90 \%$ to $15 \mathrm{MPa}$ compared to $145 \mathrm{MPa}$ in asprinted WE43. 

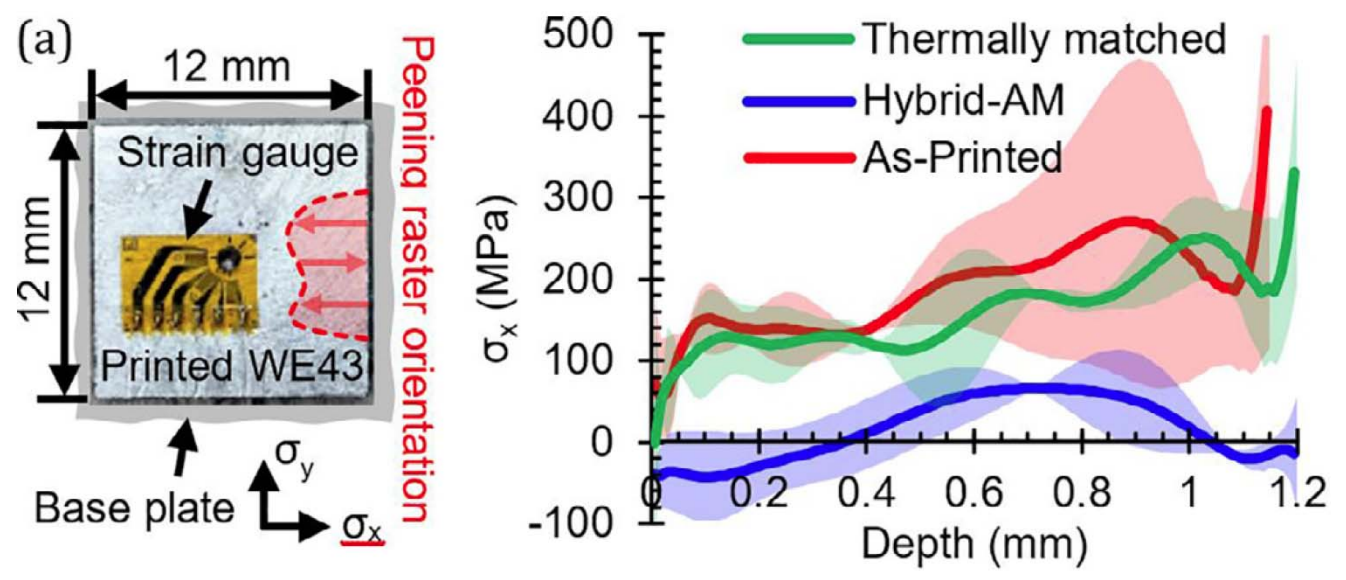

Figure 6. (a) Strain gage to measure (b) residual stress in printed WE43.

\subsection{Composition, soot formation, and density}

Larger sized WE43 components ( $\varnothing 38 \mathrm{~mm} \times 5 \mathrm{~mm}$ discs) were printed for corrosion studies. Printing larger geometries formed higher carbon concentrations from vaporization that spread across the powder bed (Fig. 7a). All as-printed WE43 components (without any pauses) accumulated the highest carbon content (15.9\%) due to prolonged exposure to vaporized soot in the print chamber. Thermally matched and hybrid-AM WE43 samples were cycled in and out of the print chamber for interlayer peening due to which lower soot content of $5.3 \%$ and $6.4 \%$ was observed, respectively. Oxygen present in the print chamber and WE43 powder reacted with vaporized magnesium to form magnesium oxide that coated the walls of the print chamber. As a result, all printed samples had lower $\mathrm{O}_{2}$ content compared to WE43 powder.
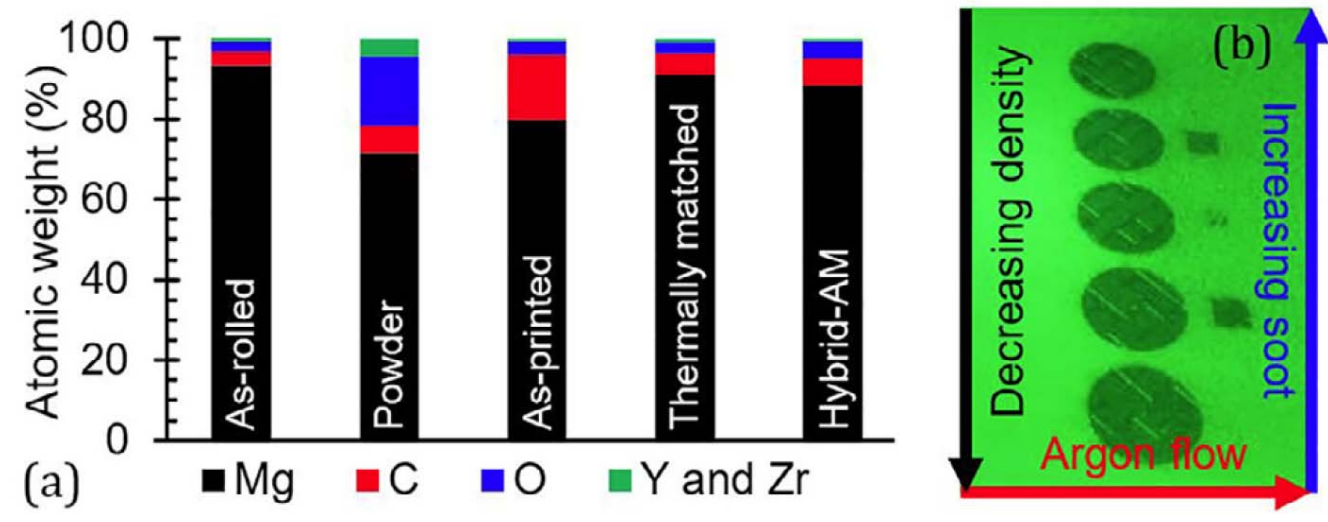

Figure 7. (a) Energy dispersive X-ray spectroscopy of printed WE43 discs and (b) soot in print chamber.

The density of discs printed for corrosion experiments depended on their location in the print chamber. Irregular argon flow across the powder bed likely caused soot to 
preferentially deposit toward one side of the baseplate. Carbon in soot having a higher melting point reduced powder vaporization, leading to highly dense printed parts on the side of the baseplate with higher soot content (Fig. 7b). High powder vaporization on the opposite side of the baseplate resulted in porosity and delamination of printed layers. However, severe plastic deformation of printed layers by interlayer ultrasonic peening flattened pores and micro-cracks, leading to a 1.6\% higher density compared to as-printed WE43. The density of as-printed, thermally matched, and hybrid-AM WE43 discs were $1.77 \pm 0.03 \mathrm{~g} / \mathrm{cm}^{3}, 1.74 \pm 0.01 \mathrm{~g} / \mathrm{cm}^{3}$, and $1.79 \pm 0.02 \mathrm{~g} / \mathrm{cm}^{3}$, respectively. All printed WE43 discs accumulated higher heat content, leading to powder vaporization and lower density compared to cuboids printed in Section 2.1.

\section{Immersion corrosion of hybrid PBF printed WE43}

All WE43 discs printed for corrosion experiments conformed to standard dimensions prescribed by ASTM G31-72. Samples were mounted in epoxy after separation from the baseplate to expose only the top surface to Hank's balanced salt solution. This enabled directional corrosion to test the effect of hybrid processing. The solution was aerated with $\mathrm{CO}_{2}$ to maintain a 7-8.5 $\mathrm{pH}$ and changed every three days. The temperature was maintained at $37-39^{\circ} \mathrm{C}$. Temperature and $\mathrm{pH}$ were measured by a ROSS Ultra Triode.

Magnesium reacts with aqueous solutions and evolves hydrogen gas and magnesium hydroxide, $\mathrm{Mg}(\mathrm{OH})_{2}$. One mole of magnesium reacts with Hank's salt solution to yield one mole of $\mathrm{H}_{2}$ gas that provides a direct and accurate measurement of the corrosion rate. The top surface of all samples was polished with 400 grit pads to ensure uniform surface finish $\left(R_{a} 8.9 \pm 2.0 \mu \mathrm{m}\right)$. Corrosion in printed samples was also compared with as-rolled WE43 that had larger equiaxed grains of $80.6 \pm 12.2 \mu \mathrm{m}$ size.

All additive manufactured samples corroded faster than the as-rolled control (Fig. 8). The corrosion rate slowed after two days due to the formation of a consistent oxide layer on the top surface. Thermally matched WE43 corroded at a rate of $62.7 \pm 3.7 \mathrm{~mm} / \mathrm{yr}$ and lost $70 \%$ mass in 7 days, meriting no further study. Localized corrosion occurred in the thermally matched WE43 in a grid pattern with a width of $5 \mathrm{~mm}$, which may likely be caused by the print cell size. Stabilized corrosion pits formed within the grids due to the action of $\mathrm{Cl}^{-}$ions in Hank's solution that dissolved the oxide layer to form magnesium chloride. Dissolution of the oxide layer on printed samples resulted in the formation of more $\mathrm{H}_{2}$ gas that prevented any further formation of oxide layer inside the printed cells. Thermally matched WE43 also had the lowest density of all printed samples that provided high surface area for corrosion. As a result, thermally matched samples corroded the fastest. As-printed WE43 with a higher density corroded slowly at a rate of $17.2 \pm 2.8 \mathrm{~mm} / \mathrm{yr}$ but also exhibited similar grid-like pattern of localized corrosion corresponding to the print cell size. Uniform corrosion with a few regions of localized corrosion appeared to be the dominant corrosion mechanism for hybrid WE43 until day 10. Corrosion pits inside print cells enlarged after 10 days and became the guiding mechanism that accelerated corrosion. Localized corrosion from hybrid-AM was also found to occur in a grid-like pattern and resulted in $50 \%$ mass loss after 11 days. Interlayer peening effectively induced barrier layers of refined grains and compressive stress that mitigated corrosion. Interlayer peening 
also reduced corrosion variability compared to as-printed and thermally matched samples that had large standard deviations.
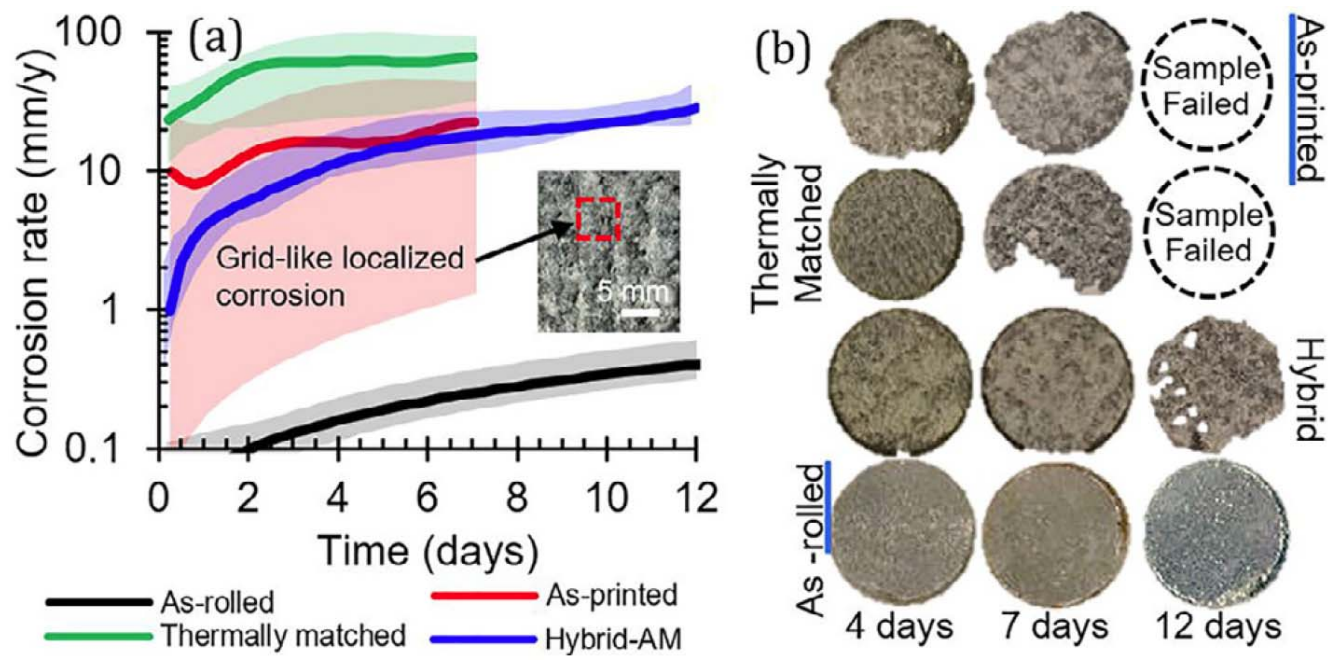

Figure 8. (a) Corrosion rate and (b) dissolution WE43 disc.

\section{Summary}

This study presents the effect of interlayer ultrasonic peening on additive manufactured WE43 to reduce corrosion rates. Interlayer peening increased corrosion resistance of printed WE43 by mitigating pitting and uniform corrosion within print cells. Severe plastic deformation from peening caused predominantly uniform corrosion with few regions of localized pitting. Favorable barrier layers formed below the surface and were identifiable by localized grain refinement and a hardened region with compressive residual stress. This research provides a pathway to develop time-resolved degradable magnesium alloys for energy, medical, and other applications subjected to harsh environments by adjusting interlayer peening during PBF. Future work will examine spatial layer treatment frequencies to establish a stress-corrosion failure theory for devices needing to maintain strength while degrading.

Declaration of competing interest - The authors declare that they have no known competing financial interests or personal relationships that could have appeared to influence the work reported in this paper.

Acknowledgments - This research was partially supported by NSF CMMI: 1846478 and performed in part in the Nebraska Nanoscale Facility (NSF ECCS: 1542182) and Nebraska Engineering Additive Technologies (NEAT) Lab supported by the Nebraska Research Initiative. Access to ultrasonic peening was facilitated by Dr. Ajit Achuthan from Clarkson University (Potsdam, NY). Matsuura USA supported modifying the Lumex Avance-25 for printing magnesium. 


\section{References}

[1] Schmidt M, Merklein M, Bourell D, Dimitrov D, Hausotte T, Wegener K, Overmeyer L, Vollertsen F, Levy GN (2017) Laser based additive manufacturing in industry and academia. CIRP Ann. - Manuf. Technol. 66(2):561-583.

[2] Sealy MP, Hadidi H, Kanger CJ, Yan XL, Cui B, McGeough JA (2019) Glocal integrity in 420 stainless steel by asynchronous laser processing. CIRP Ann. - Manuf. Technol. 68(1):189-192.

[3] Sealy MP, Hadidi H, Sotelo LD, Li WL, Turner JA, McGeough JA (2020) Compressive behavior of 420 stainless steel after asynchronous laser processing. CIRP Ann. - Manuf. Technol. 69(1): 169-172.

[4] Guo Y, Sealy MP, Guo C (2012) Significant improvement of corrosion resistance of biodegradable metallic implants processed by laser shock peening. CIRP Ann. - Manuf. Technol. 61(1):583-586.

[5] Ghiotti A, Bruschi S, Bertolini R, Perzynski K, Madej L (2020) Forming of bioabsorbable clips using magnesium alloy strips with enhanced characteristics. CIRP Ann. - Manuf. Technol. 69(1): 257-260.

[6] Bertolini R, Bruschi S, Ghiotti A, Pezzato L, Dabalà M (2018) Large strain extrusion machining of magnesium alloys for biomedical applications. Procedia CIRP 71:105-110.

[7] Gieseke M, Noelke C, Kaierle S, Wesling V, Haferkamp H (2013) Selective laser melting of magnesium and magnesium alloys. In Hort N, Mathaudhu SN, Neelameggham NR, Alderman M, (Eds.) Magnesium Technology 2013, Springer, Cham, 65-68.

[8] Abel A, Wessarges Y, Julmi S, Hoff C, Hermsdorf J, Klose C, Maier HJ, Kaierle S, Overmeyer L (2020) Laser powder bed fusion of WE43 in hydrogen-argon-gas atmosphere. Procedia CIRP 94:21-24.

[9] Karunakaran R, Ortgies S, Tamayol A, Bobaru F, Sealy MP (2020) Additive manufacturing of magnesium alloys. Bioactive Mater. 5(1):44-54.

[10] Sezer N, Evis Z, Koç M (2020) Additive manufacturing of biodegradable magnesium implants and scaffolds: review of the recent advances and research trends. J. Magn. Alloy. 11-21. https://doi.org/ 10.1016/j.jma.2020.09.014. In press.

[11] Ascencio M, Pekguleryuz M, Omanovic S (2015) An investigation of the corrosion mechanisms of WE43 Mg alloy in a modified simulated body fluid solution: the effect of electrolyte renewal. Corros. Sci. 91:297-310.

[12] Esmaily M, Zeng Z, Mortazavi N, Gullino A, Choudhary S, Derra T, Benn F, Delia F, Müther M, Thomas S (2020) A detailed microstructural and corrosion analysis of an additively manufactured magnesium alloy produced by selective laser melting. Addit. Manuf. 35:101321.

[13] Sealy MP, Madireddy G, Williams RE, Rao P, Toursangsaraki M (2018) Hybrid processes in additive manufacturing. J. Manuf. Sci. Eng. 140(6):060801.

[14] Hyer H, Zhou L, Benson G, McWilliams B, Cho K, Sohn Y (2020) Additive manufacturing of dense WE43 Mg alloy by laser powder bed fusion. Addit. Manuf. 33:101123.

[15] Wang Y, Shi J (2019) Microstructure and properties of Inconel 718 fabricated by directed energy deposition with in-situ ultrasonic impact peening. Metall. Mater. Trans. B 50:2815-2827.

[16] Li Y, Zhou J, Pavanram P, Leeflang MA, Fockaert LI, Pouran B, Tümer N, Schröder KU, Mol JMC, Weinans H, Jahr H, Zadpoor AA (2018) Additively manufactured biodegradable porous magnesium. Acta Biomater. 67:378-392. 